\title{
Innovative modified hair follicle harvesting technique with reverse rake scalp elevator for lower occipital donor area in follicular unit extraction hair transplantation
}

\author{
Chandrakant Rambhau Gharwade \\ Department of Plastic Surgery, Grant Government Medical College and Sir J. J. Group of Hospitals, Mumbai, Maharashtra, \\ India
}

Address for correspondence: Dr. Chandrakant Rambhau Gharwade, Row House-23, Puranik Villa, Swarajya Nagar, Old Mumbai-Nashik Highway, Kasheli Villege, Bhiwandi, Thane - 421 302, Maharashtra, India. E-mail: crgharwade@gmail.com

\section{ABSTRACT}

Follicular unit extraction (FUE) is one of the widely practiced minimally invasive follicular harvesting techniques employed during hair transplantation. FUE technique has an advantage of utilising lower occipital area and supra-auricular region as a safe donor area described by Unger, in addition to the standard occipital donor area used in strip method (follicular unit transplant). Despite its potential advantages such as rapid recovery, minimal scarring and reduced post-operative pain; its widespread acceptance is limited due to various factors in variable contribution like steeper learning curve and potentially higher follicular transection rates (FTRs). The main practical drawbacks in harvesting FUE from lower occipital donor region that lie inferior to the standard donor area, is its acute angle $\left(10^{\circ}-15^{\circ}\right)$ of emergent hair from scalp skin, higher variance angle $\left(15^{\circ}-35^{\circ}\right)$ between hairs below the skin and hair exit angle above the skin and comparatively loose scalp, preventing to provide stable platform for punching. Hair transplant surgeon faces difficulty in aligning and engaging the FUE punch leading to very high hair follicle transection rate, and therefore, it is not a preferred site for harvesting follicles in FUE. Authors description of modified technique using reverse rake scalp elevator helps in negating the acute angle of the hair follicles exit from scalp skin and reducing the variance angle between emergent hair and hair below the skin in lower occipital region thereby reducing FTR. Furthermore, an added advantage of reducing the overall operative time and surgeon fatigue, improve donor area healing, availability of a comparatively larger donor area which increases the confidence of the beginners. This method will be of help as it is easy to duplicate and follow by novice hair transplant surgeons and also for those who are routinely doing mega hair transplants sessions.

\section{KEY WORDS}

Hair follicle harvesting; Follicular unit extraction; hair transplantation; reverse rake scalp elevator

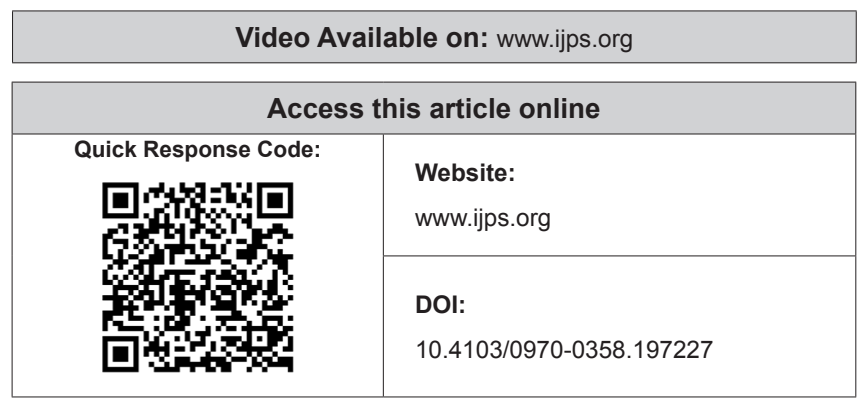

This is an open access article distributed under the terms of the Creative Commons Attribution-NonCommercial-ShareAlike 3.0 License, which allows others to remix, tweak, and build upon the work non-commercially, as long as the author is credited and the new creations are licensed under the identical terms.

For reprints contact: reprints@medknow.com

How to cite this article: Gharwade CR. Innovative modified hair follicle harvesting technique with reverse rake scalp elevator for lower occipital donor area in follicular unit extraction hair transplantation. Indian J Plast Surg 2016;49:390-6. 


\section{INTRODUCTION}

W ith the widespread use of social networking and 'selfie' culture; coupled with awareness and easy accessibility of restorative cosmetic procedures, more and more people with hair loss and baldness patterns are resorting to hair transplantation. Currently, the harvesting of hair follicles from donor scalp area is based on the two fundamental theories which are well established and globally followed, one is Orentreich's ${ }^{[1]}$ 'Donor Dominance Theory' which stated that the transplanted hair keeps the original nature of the donor site even after being transplanted and other theory of Unger' $\mathbf{s}^{[2]}$ 'Safe Donor Area' which is having a minimum of 8 hairs per $4 \mathrm{~mm}$ diameter punch. The height of this area is $70 \mathrm{~mm}$ in the occipital region, $80 \mathrm{~mm}$ in the parietal region and $50 \mathrm{~mm}$ in the temporal region. For harvesting hair follicles from scalp. ${ }^{[2]}$

Follicular unit extraction (FUE), along with its many modifications, has become one of the most popular treatments across the western world and now expanding to the faster-growing Asian and the gulf countries. ${ }^{[3]}$

A unique set of challenges exists with all FUE methods, and the most unique one is that it is a blind procedure ${ }^{[4]}$ when surgeon do it by himself manually without any assistance of digital robot like ARTAS system. Ken Williams ${ }^{[5]}$ in 2013, mentioned that despite its potential advantages such as rapid recovery, minimal scarring and reduced post-operative pain; its widespread acceptance is limited as mastering the FUE procedure can be difficult due to steeper learning curve, requirement of physical stamina and endurance, patience, excellent hand-eye coordination, a delicate touch, excellent hand motor skills, more time consuming than follicular unit transplant and potentially higher follicular transection rates (FTRs). Therefore, Rassman and Bernstein ${ }^{[6]}$ stated in 2008 is still true that there are few surgeons and centres which have mastered FUE because the procedure takes considerable time and expense to learn and to develop skills to a high standard. Other major practical difficulty in harvesting hair follicles from nuchal area was reason and advised by Dua and Dua ${ }^{[7]}$ which states that the incidence of buried graft can be reduced by avoiding the nuchal area (lower part of the scalp) where the angle of hair is very acute, and the skin has more resistance to punch. Transected follicles may regenerate as long as the hair bulb, where stem cells are located, is intact.

Harris $^{[8]}$ in 2004, pointed out that the frequent lack of association between the exit angle of the hairs and subcutaneous course of the follicles is particularly problematic when this is coupled with frequent changes in follicular direction and the acuteness of the angle, then the FTR is more. Bernstein et al. ${ }^{[9]}$ in 2004, found that in almost all instances, the angle of emergent hair is more acute than the angle of follicle in the dermis and they advised the incision must obviously anticipate this and be oriented in the direction of follicle rather than the visible hair. Rassman et al. ${ }^{[10]}$ reported the variance angle of the hair below the skin when compared to the hairs exit angle above the skin range between $15^{\circ}$ and $35^{\circ}$. In FUE, as it is a blind procedure and the hair bulb cannot be visualised during the punch and transection occurs at a higher rate owing to unanticipated follicular unit splay, curvature and abrupt turns. Therefore, surgeons must carefully observe visual clues, such as follicular direction change or poor forceps placement, to assure the lowest transection rate possible. ${ }^{[2]}$ The FTR also depends on the patient's skin characteristics and the inside diameter of the punch and the ranges is from $2 \%$ to $8 \%\left[{ }^{11]}\right.$ which is an acceptable FTR for FUE everywhere.

The cosmetic result depends not only on the graft type (single-hair grafts or follicular units), the survival rate of the transplantation and the skill of the surgeon, but also on the number of grafts one can transplant, quoted by Gho. ${ }^{[12]}$ Thus, advances towards increasing the number of complete follicular units harvested by reducing the FTR help to achieve the optimum desired result.

\section{Safe donor area with special consideration for lower occipital donor area}

With widespread application of FUE and most of the patients demanding an FUE mega-sessions with maximum coverage of the recipient bald area, it becomes essential to expand the donor area for harvesting more number of hair follicles. In general, the appropriate location of the scalp donor area is that described by Unger. ${ }^{[2]}$ However, with FUE the boundaries can be extended to include the supra-auricular region and lower occiput. These are areas where surgeon would not often consider harvesting a strip, yet they are good for obtaining finer hairs for use in the hairline or anterior temples. ${ }^{[13]}$

The information on the subject of true safe donor area is mainly anecdotal and haphazard as there are no sufficiently exhaustive studies to address this issue. Knudsen $^{[13]}$ in 2004 stated that a safe donor area is an area that is expected to be permanently covered with hair 
for a lifetime and therefore, provide permanent coverage when transplanted to the recipient area. However, no safe donor area guarantees that the hair will be permanent. There exist only safe donor areas anticipated to have no invasion of alopecia. Thus, the definition of safe donor area, an area in which no progression of permanent hair loss occurs, is the underlying basis for practice of hair transplantation surgery. ${ }^{[13]}$ Rassman and Carson ${ }^{[14]}$ stated that though superior and lateral boundaries of safe donor area are fixed and well known, its inferior border's exact site is still slightly controversial, since the inferior hairline may move upwards with the passage of time.

Different regions of the scalp exhibit different directions of the hair follicles as well as varying exit angles from the scalp. An angle of $45^{\circ}-60^{\circ}$ in the posterior mid-scalp which is the conventional donor area for FUE. In contrast, hairs are directed downwards towards the nape of neck with an angle as acute as $15^{\circ}-20^{\circ}$, which makes it difficult for surgeon to keep his head position at one place for longer duration to concentrate and focus on hair follicles to be harvested in lower occipital region (LOR) leading to surgeons early fatigue. Furthermore, there is a need for a stable platform for proper engagement of the punch while harvesting follicles in an FUE session using micromotor drill powered punches which is naturally provided by underlying skull draped by tightness of scalp skin. However, in lower occipital area, just superior to the nape of neck, there is inwards turning of nuchal skull bone and the overlying scalp skin is comparatively lax with increased skin mobility which provides a less stable surface for the FUE punch and creates difficulty in engaging and aligning the punch during follicular harvesting phase, which increases the FTR. This is precisely the reason why patients with a loose scalp are not the ideal candidates to undergo hair transplantation by FUE, said by Barusco. ${ }^{[15]}$

\section{MATERIALS AND METHODS}

Hairs were trimmed with an electric trimmer with minimum size setting and povidone iodine scrub head bath was given. Pre-operative markings [Figure 1] of the safe donor area as described by Unger ${ }^{[2]}$ were done in sitting position. The LOR, marked as red-shaded area and labelled as Area 'b', where the hair follicles make an acute angle with the scalp, was marked approximately as a $2.5 \mathrm{~cm}$ wide zone, which surface anatomically corresponds to approximately between superior and inferior nuchal lines of skull, where scalp skin generally drape inwards over the nuchal skull, which makes

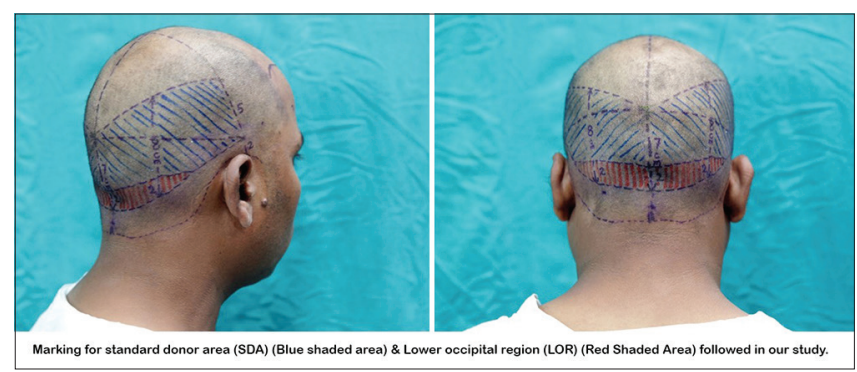

Figure 1: Pre-operative markings on patients

this region practically difficult position to harvest hair follicles resulting in more FTR, hence avoided by majority of beginners hair transplant surgeon but gives ultimately increase number of harvested hair follicles as an advantage in addition to the follicles harvested from standard donor area (SDA) [Figure 1]. Rest of the donor area was labelled as SDA, marked as blue-shaded area (Area 'a'), is a preferred SDA by the majority of hair transplant surgeons.

Field block local anaesthesia was administered after painting and draping the donor area in prone position. Micromotor powered drill use with FUE punches ( 0.9 and $1 \mathrm{~mm}$ sizes) for harvesting the hair follicles from donor hair bearing area.

Author used conventional method of follicle harvesting in group A patients for both "area a" and "area b",and the Goup B patients he used his modified technique using using 'reverse rake retractor', designed and developed by the author [Figure 2], for LOR (Area 'b'). After harvesting, each hair follicles were visually evaluated and separated in different petri dishes as complete or incomplete grafts (transected hair follicle) for each Area 'a' and Area 'b' [Figure 3].

\section{Specifications of reverse rake scalp elevator surgical instrument [Figures 2, 4 and 5]}

Reverse rake scalp elevator is made of stainless steel and comprises three parts such as handle, tip and middle portion:

1. Handle - Five inches length, $0.5 \mathrm{~cm}$ diameter round-shaped handle with proximal 3 inches of the handle made of fine course surface for better grip (preventing slipping of the hand grip)

2. Tip - Six fine tip curved hook prongs equally spaced along and attached to the horizontal length of $3 \mathrm{~cm}$ bar

3. Middle portion - Consist of two horizontal bars, each of $3 \mathrm{~cm}$ long which are connected with each other with the help of equally placed six semicircular bars having inner radius of approximately $0.5 \mathrm{~cm}$. This 


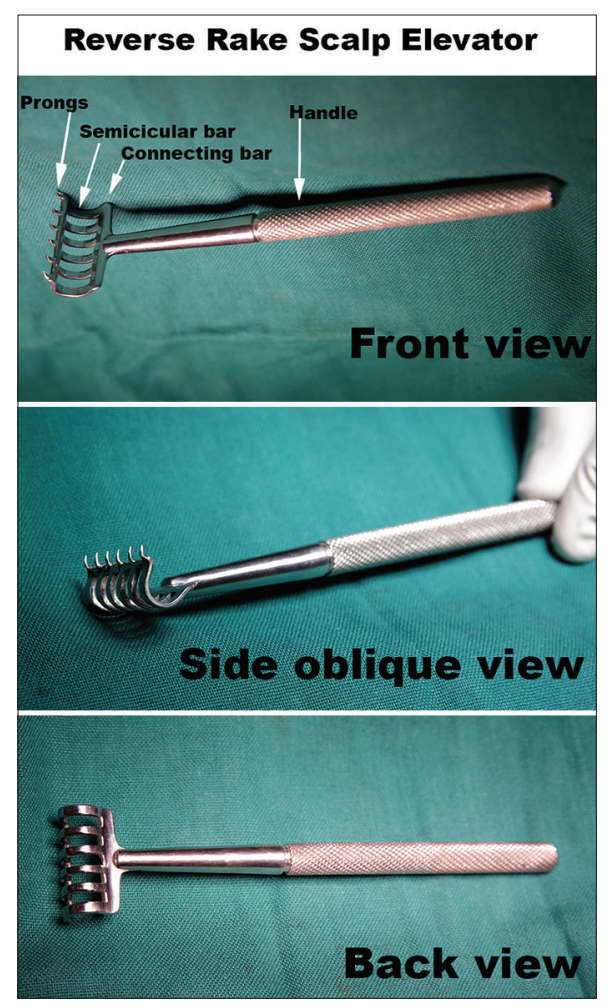

Figure 2: Author's Reverse Rake Scalp Elevator

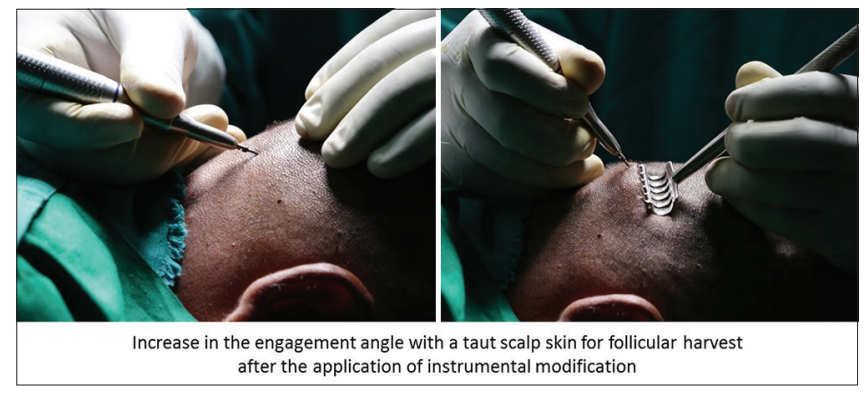

Figure 4: Intra-operative angle change after application of Reverse Rake Scalp Elevatore

middle portion is joined proximally with the handle and distally contains tip portion as stated above.

\section{Principle and method for application of reverse rake scalp elevator [Figures 4 and 5] (Video - 1)}

Figure 4 shows the way of holding and using the reverse rake scalp elevator instrument during surgery. This instrument held in non-dominant hand. At first, it is fine sharp small prongs has to engaged in scalp like a skin hook and then it is to be turn $180^{\circ}$ to exert a forwards and upwards pressure by it is middle part of multiple semicircular bars resulting in the lifting the scalp skin using sea saw like action with semicircular bars act as lever as it rest on scalp as shown in Figures 4 and 5 . This maneuver provide stable platform by stretching and tightening the scalp skin in LOR for FUE harvesting, leading

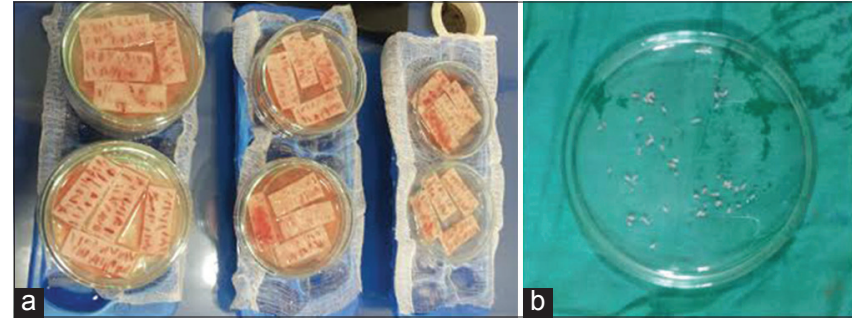

Figure 3: (a) Complete hair follicles harvested and (b) Transected hair follicles harvested

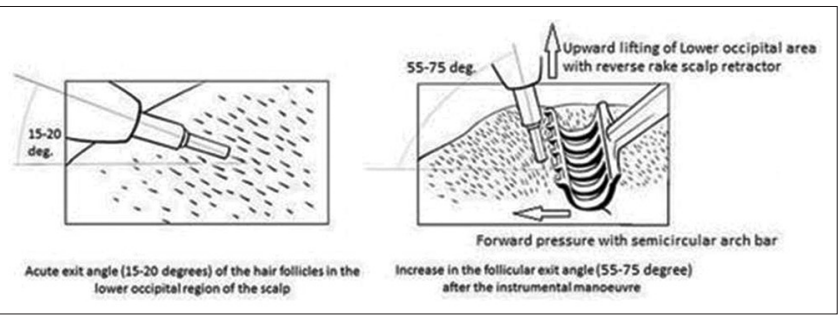

Figure 5: Illustration showing mechanism and advantage of using Reverse Rake Scalp Elevator

to reduces the variance angle of hair and also change the exit angle of emergent hair to near perpendicular angle (about $55^{\circ}-75^{\circ}$ ) from acute angle (about $15^{\circ}-20^{\circ}$ ) as illustration shown in Figure 5. This facilitated proper engagement of the punches with the emerging hair from taut and stable scalp skin as one encountered in other remaining SDA.

\section{OBSERVATIONS}

Totally twelve young male patients with androgenic alopecia willing to undergo FUE hair transplantation were enrolled for the surgery. We randomly made two groups (Group A and B), comprises six patients in each group.

In this study, extracted hair follicle's transection is referred to potential damage to the lower portion of hair follicle during FUE often the hair bulb where stem cells are located, which will prevent it from generate new hair, and this damage greatly increases the risk that the follicle will not grow, or survive, once transplanted. Complete healthy grafts were used for implantation at recipient site, and incomplete/transected grafts were discarded.

The hair FTR was calculated as number of transected follicles per 100 graft extracted, for the each marked region (Area 'a' and Area 'b') separately. 
For statistical significance, data were analysed by unpaired $t$-test and $P<0.05$ was considered as statistically significant value.

\section{RESULTS}

1. Average FTR from SDA in Group 'A' and Group 'B' patients was 2.78 and 2.60 , respectively [Table 4]. Hair follicles harvested from SDA in Group 'A' and Group 'B' patients were comparable, and the difference was not statically significant ( $\mathrm{df}=10, t=1.0379$, $P=0.3238$ ) [Table 1]

2. Average FTR from lower occipital donor area in Group 'A' and Group 'B' patients was 14.40 and 5.10, respectively [Table 4]. When hair follicle harvested from lower occipital donor area of Group ' $A$ ' and Group 'B' patients were compared and we observed highly significant statistical difference between these two groups ( $\mathrm{df}=10, t=18.77, P<0.0001)$ [Table 2]

3. Average FTR from total scalp donor area in Group 'A' and Group 'B' patients was 5.10 and 3.10, respectively [Table 4]. Total hair follicles harvested in Group ' $\mathrm{B}$ ' were significantly more than Group 'A' (df $=10, t=11.17, P<0.0001)$ [Table 3].

By applying statistical methods ( $P$ value, unpaired $t$-test and percentage), shows increasing contribution from the LOR, overall less follicular transection of donor hair follicles along with total harvested hair follicles increased which ultimately increase success of hair transplant

\section{DISCUSSION}

In conventional method, the hair follicles transected are proportionately more when harvesting is from the LOR. By applying our modified extraction technique, harvested follicles transected are proportionately less. In above study, the average FTR from the lower occipital area prior to the use of reverse rake scalp elevator instrument with our modification technique was $14.40 \%$ which was reduced to $5.10 \%$ after its application, due to decrease in variance angle of hair below the skin when compare to the hair exit angle above the skin ${ }^{[8,10]}$ and negating the acute angle of the hair follicles with scalp skin. Author's results are in comparison with Harris results of $2 \%-8 \%$ of FTR. ${ }^{[11]}$

By applying instrumental modification with the help of reverse rake scalp elevator, author found that harvested hair follicles from nuchal area with less buried graft and transected follicles as oppose to Dua and Dua ${ }^{[7]}$ who advised to avoid nuchal area for follicle harvest to reduce incidence of buried graft where the angle of hair is very acute and the skin has more resistance to punch.

Table 1: Comparison of hair follicles harvested from standard donor area (Area 'A') in follicular unit extraction

\begin{tabular}{|c|c|c|c|c|c|}
\hline \multicolumn{3}{|c|}{ Group A (n=6) } & \multicolumn{3}{|c|}{ Group B $(n=6)$} \\
\hline $\begin{array}{l}\text { Intact hair follicles } \\
\text { harvested }\end{array}$ & $\begin{array}{c}\text { Transected hair } \\
\text { follicles harvested }\end{array}$ & $\begin{array}{c}\text { Total hair follicles } \\
\text { harvested }\end{array}$ & $\begin{array}{c}\text { Intact hair follicles } \\
\text { harvested }\end{array}$ & $\begin{array}{c}\text { Transected hair } \\
\text { follicles harvested }\end{array}$ & $\begin{array}{c}\text { Total hair follicles } \\
\text { harvested }\end{array}$ \\
\hline 1762 & 48 & 1810 & 1747 & 43 & 1790 \\
\hline 1731 & 44 & 1775 & 1796 & 52 & 1848 \\
\hline 1610 & 48 & 1658 & 1702 & 56 & 1758 \\
\hline 1628 & 52 & 1680 & 1757 & 49 & 1806 \\
\hline 1663 & 47 & 1710 & 1783 & 42 & 1825 \\
\hline 1668 & 49 & 1717 & 1763 & 40 & 1803 \\
\hline
\end{tabular}

$\mathrm{df}=10, t=1.0379, P=0.3238$

Table 2: Comparison of hair follicles harvested from lower occipital donor area (Area 'B') by conventional method and our modified technique in follicular unit extraction

\begin{tabular}{|c|c|c|c|c|c|}
\hline \multicolumn{3}{|c|}{$\begin{array}{l}\text { Hair follicles harvested by conventional extraction method of } \\
\text { FUE (Group A) (n=6) }\end{array}$} & \multicolumn{3}{|c|}{$\begin{array}{l}\text { Hair follicles harvested by our modified extraction technique of } \\
\text { FUE (Group B) }(n=6)\end{array}$} \\
\hline $\begin{array}{l}\text { Intact hair follicles } \\
\text { harvested }\end{array}$ & $\begin{array}{l}\text { Transected hair } \\
\text { follicles harvested }\end{array}$ & $\begin{array}{l}\text { Total hair follicles } \\
\text { harvested }\end{array}$ & $\begin{array}{l}\text { Intact hair follicles } \\
\text { harvested }\end{array}$ & $\begin{array}{l}\text { Transected hair } \\
\text { follicles harvested }\end{array}$ & $\begin{array}{l}\text { Total hair follicles } \\
\text { harvested }\end{array}$ \\
\hline 410 & 60 & 470 & 455 & 23 & 478 \\
\hline 396 & 62 & 458 & 460 & 22 & 482 \\
\hline 338 & 64 & 402 & 407 & 25 & 432 \\
\hline 350 & 60 & 410 & 414 & 21 & 435 \\
\hline 353 & 62 & 415 & 400 & 22 & 422 \\
\hline 362 & 63 & 425 & 426 & 25 & 451 \\
\hline
\end{tabular}

$\mathrm{df}=10, t=18.77, P<0.0001$. FUE: Follicular unit extraction 
Table 3: Comparison of hair follicles harvested from total donor area (Area ' $C$ ') $=$ standard donor area $($ Area 'A') + lower occipital donor area (Area 'B') by conventional method and our modified technique in follicular unit extraction

\begin{tabular}{|c|c|c|c|c|c|}
\hline \multicolumn{3}{|c|}{$\begin{array}{l}\text { Hair follicles harvested by conventional extraction method of } \\
\text { FUE (Group A) (n=6) }\end{array}$} & \multicolumn{3}{|c|}{$\begin{array}{l}\text { Hair follicles harvested by our modified extraction technique of } \\
\text { FUE (Group B) }(n=6)\end{array}$} \\
\hline $\begin{array}{l}\text { Intact hair follicles } \\
\text { harvested }\end{array}$ & $\begin{array}{l}\text { Transected hair } \\
\text { follicles harvested }\end{array}$ & $\begin{array}{l}\text { Total hair follicles } \\
\text { harvested }\end{array}$ & $\begin{array}{l}\text { Intact hair follicles } \\
\text { harvested }\end{array}$ & $\begin{array}{l}\text { Transected hair } \\
\text { follicles harvested }\end{array}$ & $\begin{array}{l}\text { Total hair follicles } \\
\text { harvested }\end{array}$ \\
\hline 2172 & 108 & 2280 & 2202 & 66 & 2268 \\
\hline 2127 & 106 & 2233 & 2256 & 74 & 2330 \\
\hline 1948 & 112 & 2060 & 2109 & 81 & 2190 \\
\hline 1978 & 112 & 2090 & 2171 & 70 & 2241 \\
\hline 2016 & 109 & 2125 & 2183 & 64 & 2247 \\
\hline 2030 & 112 & 2142 & 2189 & 65 & 2254 \\
\hline
\end{tabular}

$\mathrm{df}=10, t=11.17, P<0.0001$. FUE: Follicular unit extraction

Table 4: Comparison between conventional method and our modified follicular unit extraction technique, for harvested hair follicular transection rate following extraction

\begin{tabular}{|c|c|c|c|c|c|c|}
\hline \multicolumn{7}{|c|}{ FTR } \\
\hline \multirow{2}{*}{$\begin{array}{l}\text { Serial } \\
\text { number }\end{array}$} & \multicolumn{3}{|c|}{ Conventional method $(n=6)$} & \multicolumn{3}{|c|}{ Our modification method $(n=6)$} \\
\hline & $\begin{array}{c}\text { Standard } \\
\text { donor area }\end{array}$ & $\begin{array}{c}\text { Lower occipital } \\
\text { donor area }\end{array}$ & $\begin{array}{c}\text { Total donor } \\
\text { area }\end{array}$ & $\begin{array}{c}\text { Standard } \\
\text { donor area }\end{array}$ & $\begin{array}{c}\text { Lower occipital } \\
\text { donor area }\end{array}$ & $\begin{array}{c}\text { Total } \\
\text { donor area }\end{array}$ \\
\hline 1 & 2.65 & 12.76 & 4.73 & 2.40 & 4.81 & 2.91 \\
\hline 2 & 2.47 & 13.53 & 4.74 & 2.81 & 4.56 & 3.17 \\
\hline 3 & 2.89 & 15.92 & 5.43 & 3.81 & 5.78 & 3.69 \\
\hline 4 & 3.09 & 14.63 & 5.35 & 2.71 & 4.82 & 3.12 \\
\hline 5 & 2.74 & 14.93 & 5.12 & 2.30 & 5.21 & 2.84 \\
\hline 6 & 2.85 & 14.82 & 5.22 & 2.21 & 5.54 & 2.88 \\
\hline $\begin{array}{l}\text { Average } \\
\text { FTR }\end{array}$ & 2.78 & 14.40 & 5.10 & 2.60 & 5.10 & 3.10 \\
\hline
\end{tabular}

FTR: Follicular transection rate

As Zontos ${ }^{[16]}$ pointed out that, as the obliquity of punch alignment increases, the resulting small defects from the punches become more elliptical and thereby the effective raw area also increases. If the alignment and engagement are at a near-perpendicular angle, as seen in the crown region, the defects become more or less circular and the effective raw area is less. As a result, healing is improved, and scarring is reduced, thereby facilitating multiple sittings of FUE, this is exactly what happens with the application of author's technique, so the better and fast healing of donor area.

Bertram and Damkemg, Yamamoto ${ }^{[17,18]}$ suggested the need for further research into the refinements, improvement of instrumentation and efficacy of FUE technique; author tried the same and presenting a novel FUE modification and instrumentation technique of harvesting follicular units from the LOR with a significantly reduced FTRs and increased number of complete grafts harvested.

With the ability to use the lower aspect of the scalp to harvest donor hair follicles, a bigger field is offered to the beginners who may have higher hair follicle transection rate. Authors' technique is also useful for budding hair transplant surgeons doing FUE in LOR where scalp skin is generally loose, which can be stretched and made tight with the application of reverse rake scalp elevator, to prevent as well as to reduce the damage to the harvesting hair follicles due to movements during engagement with FUE punch used along with power drill.

In subjective evaluation, it was found that authors technique reduces the overall operative time and surgeon's fatigue in harvesting hair follicles in FUE for lower occipital donor area in comparison with the conventional method for harvesting hair follicles from lower occipital area, which are also some of the important factors implicated in causing higher FTR.

\section{CONCLUSION}

Till now, many practical difficulties in harvesting hair follicles from lower occipital area were not address properly, but due to the application of authors modified follicular harvesting technique using reverse rake scalp elevator, many unanswered questions are solved.

In Conclusion, with this modified method, the donor transected hair follicle wastage will be less with reduce 
FTR, donor area healing improves and overall total usable healthy hair follicles harvested will be more, which ultimately assures better success cosmetic result of patients FUE hair transplant. It reduces the overall operative time and surgeon's fatigue. A larger donor area is available that increases the confidence of the beginners. The application of this technique in harvesting hair follicles in FUE is quite easy, without much of a learning curve. This method will be of help as it is easy to duplicate and follow by novice hair transplant surgeons.

In this era of FUE mega sessions, hair transplant surgeons can apply this method to effectively harvest increase number of ultimate healthy follicular units from vast available scalp donor area in FUE hair transplantation.

\section{Acknowledgement}

Author would like to express his gratitude to following seniors, colleagues' \& friends for their support \& help for practically converting his thoughts in reality.

- Dr. Shamol Banerjee Associate Professor \& Head, Department of Plastic Surgery, Grant Medical College \& Sir J.J. Group of Hospitals, Mumbai, for believing my concept \& permitted author for carrying out this our modification technique.

- All Plastic Surgery Senior Residents in the department for assisting in the procedure \& helping author in patients perioperative management \& Follow up.

- Dr. Hrishikesh Khadilkar, M.D. PSM, Associate Professor in PSM, Regional Cancer Hospital \& Govt. Medical College, Aurangabad for helping statistically analyzing \& interpretation observed data.

- Mr. Narendra Borlepwar, Artist \& Photographer at St. George's hospital, Mumbai for taking photographs \& Videos \& making illustratins for this study.

- Dr. Ameya Bindu, Dr. Mukund Parchandekar, Dr. Hrishikesh Khadilkar, Grant Medical College \& Sir J.J. Group of Hospitals, Mumbai, for helping author in assisting writing.

- Medical Superintendent and OT staff, nurses of St. George's Hospital.

\section{Declaration}

The instrument is under the process of patenting.
Financial support and sponsorship

Nil.

\section{Conflicts of interest}

There are no conflicts of interest.

\section{REFERENCES}

1. Orentreich N. Autografts in alopecias and other selected dermatological conditions. Ann NY Acad Sci 1959;83:463-79.

2. Unger $W$. Delineating the safe donor area for hair transplanting. J Am Acad Cosmet Surg 1994;4:239-43.

3. Burke KE. Hair loss. What causes it and what can be done about it. Postgrad Med 1989;85:52-8, 67-73, 77.

4. Bicknell LM, Kash N, Kavouspour C, Rashid RM. Follicular unit extraction hair transplant harvest: $A$ review of current recommendations and future considerations. Dermatol Online J 2014;20. pii: Doj_21754.

5. Williams KL Jr. Current practices and controversies in cosmetic hair restoration. Dermatol Surg 2013;39:797-801.

6. Rassman WR, Bernstein R. Hair Loss and Replacement for Dummies. Indiana: Wiley Publish Inc.;2008. p. 201.

7. Dua A, Dua K. Follicular unit extraction hair transplant. J Cutan Aesthet Surg 2010;3:76-81.

8. Harris JA. The safe system: New instrumentation and methodology to improve follicular unit extraction (FUE). Hair Transplant Forum Int 2004;14:162-4.

9. Bernstein RM, Rassman WR, Anderson KW. FUE Megassions: Evolution of a technique. Hair Transplant Forum Int 2004;14:97-9.

10. Rassman W, Pak J, Kim J (2016) Follicular Unit Extraction: Evolution of a Technology. J Transplant Technol Res 6: 158. doi: 10.4172/2161-0991.1000158.

11. Harris J. Conventional FUE in hair transplantation. In: Unger W, Shapiro R, Unger R, Unger M, Eds. London: Informa Healthcare; 2011,p. 291-6.

12. Gho CG, Martino Neumann HA. Donor hair follicle preservation by partial follicular unit extraction. A method to optimize hair transplantation. J Dermatolog Treat 2010;21:337-49.

13. Knudsen RG. The donor area. Facial Plast Surg Clin North Am 2004;12:233-40.

14. Rassman WR, Carson S. Micrografting in extensive quantities. The ideal hair restoration procedure. Dermatol Surg 1995;21:306-11.

15. Barusco MN. The no shave technique for FUE. Hair Transplant 360 Degree Vol. 3. New Delhi: Jaypee Brothers Medical Publishers Itd.; 2014. p. 238.

16. Zontos G. How the OutgrowthAngle of the Hair Follicles Influences the Donor Area Injury Using FUE - A Mathematical Approach to the Problem. Available from: http://www.haarklinikken.dk/ cgi-files/mdmgfx/file-896-418802-25165.pdf. [Last accessed on 2014 Oct].

17. Bertram NG, Damkemg P. Follicular unit extraction: Experience in Chinese population. Hair Transplant Forum Int 2009;19:14. Available from: http://www.forhair.com/pdfs/CIT\%20 info. pdf. [Last accessed on 2010 Jan 2015].

18. Yamamoto K. Intra-operative monitoring of the follicular transection rate in follicular unit extraction. Hair Transplant Forum Int 2008;18:175. 